\title{
The Influence of First-year Students' Place of Residence before Entering the University on the Process of Adaptation at the Higher Education Institution
}

\author{
Alexander Smirnov \\ Candidate of Psychological Sciences, Associate Professor, Associate Professor at the Chair of Pedagogics and \\ Pedagogical Psychology P.G. Demidov Yaroslavl State University; asmirnov1970@bk.ru
}

Mariya Yurkina

Postgraduate Student at the Chair of Pedagogics and Pedagogical Psychology P.G. Demidov Yaroslavl State University; msyurkina@mail.ru

\section{Dmitriy Smirnov}

Candidate of Legal Sciences, Associate Professor, at the Chair of Labor and Financial Law P.G. Demidov Yaroslavl State University; Dima_Smirnov@bk.ru

Doi:10.5901/mjss.2015.v6n6s5p313

\begin{abstract}
The paper considers structural and functional characteristics of higher education institution adaptation of first-year students. In particular, the influence of such social and demographic characteristic of first-year students as the place of residence before entering the university on the process of students' adaptation to the higher education institution is described. The specific character of progress of social, didactic and professional adaptation in the groups of students who lived in Yaroslavl region and in other regions before entering the university is identified. The influence of the first-year students' place of residence before matriculation on structural and functional features of higher education institution adaptation of students has been empirically grounded: the analysis of differences of adaptation structures and basic qualities using the express $\chi 2$ method was performed. As a result of work, the distinctions at the statistically significant level between the groups described have been found. In particular, students coming from other regions have lower indices in social and professional components of adaptation as compared to the first-year students coming from the region. The personality structures of the subdivided groups were also analyzed and described. Within the personality structure of students coming from other regions, the parameter "Expectation of internal control" is in a positive correlation and it determines all three components of higher education institution adaptation. Therefore, by influencing this parameter, we can at the same time promote the enhancement of all constituents of students adaptation as a total.
\end{abstract}

Keywords: adaptation to higher education institution, students, social and demographic characteristics, non-resident students.

\section{Introduction}

The questions of improving the efficiency of learning correspond to the general direction of education development strategy in Russia. This is why studying the higher education institution adaptation is relevant and significant at the contemporary stage of development of higher education.

Higher education institution adaptation is referred to a kind of social adaptation by many authors. This process can be determined as elaborating an optimum mode of student's personality purposeful functioning (Karpov et al., 2003).

The category of higher education institution adaptation is described in the works of Russian and foreign researchers (Karpov et al., 2003; Povarenkov, 2008; Schmidt, 2005; Smith, 2008). The adaptation of students is viewed as a continuous process and result of an individual's adapting to changing social conditions (Hertel, 2002), or as a process of development which takes place as a result of overcoming the crisis periods occurring during the personality's professionalization (Povarenkov, 2008), or as adapting to new conditions of the learning activity (Trockel et. al., 2000). Importantly, this process implies the development of a student's personality (Smith, 2008).

In the structure of the above process, we study the following components: an individual's adapting to new social conditions; the development during the personality's professionalization; adaptation to the conditions of learning activity 
(Smirnov \& Yurkina, 2015).

Many researchers point out the annual increase of the percentage of non-resident students in the total quantity of the first-year students (Khasyanova \& Saltanova, 2010). This group is a special category of the first-year students. For the local students, when they enter a higher education institution, it is only the geographical location of the education institution within one city and the kind of learning activity that change, i.e. they live in a familiar to them social environment and they use the accumulated social and cultural capital. The non-residents become migrants in a strange city and have to live independently. That is, this group of students has to adapt not only to the higher education institution but also to the city, to new conditions of life (Chapdelaine \& Alexitch, 2004).

Most studies conducted in this direction mainly deal with migrants and resettlers (Nishimura, T. and Sakurai, S, 2013). The process of non-residents entering the new environment yet remains understudied. Therefore, this topic is relevant and sought for.

\section{Research Methods}

\subsection{Empirical methods}

We used the following techniques and methods as diagnostic tools: questionnaire "Diagnostics of social and psychological adaptation" (C. Rogers, R. Diamond, as adapted by A.K. Osnitskiy), "Motivation of learning at the higher education institution" technique (T.I. llyina), coping behavior estimation technique (R. Lazarus, S. Folkman), "Students' adaptation to the higher education institution" questionnaire (M.S. Yurkina), "Personality orientation" questionnaire (V. Smekala, M. Kuchera), "Estimation of a personality's adaptedness condition" questionnaire.

The analysis of empirical data has been conducted using the methods of parametric statistics: checking of normality of distribution (using the $X^{2}$ criterion), determining the validity and significance of distinctions according to Student's t-test, correlation analysis according to Pearson's $\rho$-test, measuring the non-linear links between variables (correlation ratio $\eta^{2}$ ). The method of stating the basic components was used. For counting the extent of organization of correlation structures, the indices suggested by A.V. Karpov were used.

\section{Results and Discussion}

We have subdivided the non-resident first-year students according to the distance of their place of residence before matriculation into students from Yaroslavl region and ones from other regions. The sample was constituted by first-year students of P.G. Demidov Yaroslavl State University of the faculties of psychology, biology and ecology, physics, economics, and law of 2013-2014 year of entry. In particular, 352 students coming from the home region were included and 358 ones - from other regions. This proportion of students in the groups corresponds to the proportion of first-year students in the faculties, which confirms the representativeness of our sampling. The age of the tested ones ranges from 17 to 24 . Table 1 presents the distinctions according to the adaptedness level parameter which are statistically significant.

Table 1. The distinctions in the adaptedness level between students coming from Yaroslavl region (YR) and ones coming from other regions (OR)

\begin{tabular}{|l|c|c|c|c|}
\hline \multirow{2}{*}{ Parameter } & \multicolumn{2}{|c|}{ Average } & \multirow{2}{*}{ Student t-test } & \multirow{2}{*}{$\mathrm{p}$} \\
\cline { 2 - 3 } & YR & OR & & \\
\hline Social adaptation & 41.10 & 39.34 & 1.34 & $\mathrm{p}<0.05$ \\
\hline Professional adaptation & 50.27 & 48.41 & 1.38 & $\mathrm{p}<0.05$ \\
\hline Distancing & 8.46 & 9.69 & 2.36 & $\mathrm{p}<0.01$ \\
\hline Acceptance of responsibility & 7.33 & 7.98 & 1.61 & $\mathrm{p}<0.05$ \\
\hline Positive re-evaluation & 11.71 & 12.67 & 1.53 & $\mathrm{p}<0.05$ \\
\hline Satisfaction by situation & 12.60 & 12.07 & 1.29 & $\mathrm{p}<0.05$ \\
\hline Satisfaction by health & 15.21 & 14.48 & 1.58 & $\mathrm{p}<0.05$ \\
\hline Satisfaction by activity & 14.88 & 14.16 & 1.46 & $\mathrm{p}<0.05$ \\
\hline
\end{tabular}

The students who before matriculation used to live in a region other than the one housing the educational institution have lower indices in the parameters of "Social adaptation" and "Professional adaptation" as compared to the group of students coming from Yaroslavl region (Table 1). Considering the distinctions of coping strategies in these groups, we 
should point out that the learners coming from other regions have higher indices as compared to the remaining students in the parameters of "Distancing", "Acceptance of responsibility" and "Positive re-evaluation" (Table 1). This fact confirms that in a frustrating situation, it is most inherent in this group of students to make cognitive efforts of distancing themselves from the situation and reducing its significance while at the same time bearing in mind their roles in the problem and, in particular, focusing on positive moments which the situation brings for a personality. Such a type of behavior can be a consequence of the fact that this group is the most isolated from its previous social circle and has to independently resolve any problems occurring of both learning and daily life character. Students coming from other regions as compared to the first-year students from the region have lower indices according to the level of satisfaction by the situation, their health and way of life, as well as by their activity. This fact can result from moving to another region, as the students get to new social, daily life, and study conditions and have to adapt to them, which is a stress for the organism, hence the emotional background and perception of the current situation have a negative character.

Next, we performed the correlation analysis within each group. We are going to consider the correlations with scales "Social adaptation", "Didactic adaptation", "Professional adaptation" only.

In the personality structure of students coming from the region, the component of didactic adaptation correlates positively to such parameters as "Motivation to obtain knowledge" $(r=0.36 ; p<0.01)$, "Motivation to receive a diploma" $(r=0.44 ; p<0.001)$, "Self-control" $(r=0.30 ; p<0.05)$, "Problem solution planning" $(r=0.30 ; p<0.05)$ and "Positive reevaluation" $(r=0.23 ; p<0.05)$. Thus, we can conclude that these characteristics are interrelated and as one index increases, the other one will go up, respectively. However, at this stage of analysis, we cannot come to any conclusions as to which exactly of these parameters determines the increase of the other ones.

Let us consider the social component of higher education institution adaptation. Numerous positive correlations of this characteristics and scales of other techniques were revealed at the stage of correlation analysis. Let us indicate the correlations of the "Social adaptation" scale at $p<0.001$ significance level: "Satisfaction by activity" $(r=0.43)$ and "Emotional comfort" ( $r=0.49)$. Therefore, the more a student coming from the region is happy with the new activity type and the more comfortably he feels in the new conditions, the higher social adaptation indices he is going to have, and vice versa, accordingly.

It has also been found out that the professional component of adaptation has numerous positive correlations with parameters from other techniques. Let us discuss the positive correlations with this component at $p<0.001$ significance level. The following mutual links of the above parameter were revealed: "Satisfaction by activity" ( $r=0.43)$, "Acceptance of oneself" ( $r=0.49)$, "Expectation of internal control" $(r=0.45)$. Thus, as the professional adaptedness indices increase, the self-acceptance, realization of significance of one's efforts in problem solving will go up, the assessment of one's activity will be higher, too, and vice versa, accordingly.

In the personality structure of students coming from other regions, what concerns the "Didactic adaptation" parameter, there is a negative correlation with "Motivation to receive a diploma" scale $(r=-0.34 ; p<0.01)$. Therefore, if students coming from other regions enter a higher education institution in order to formally get an education, the level of the didactic component will be low, and vice versa, accordingly. At $p<0.001$ significance level, such coping strategy as "Self-control" correlates to the said parameter positively ( $r=0.42)$. Thus, the more adapted in the learning process a student is, the more characteristic it is for him to make efforts to control his feelings and actions in a frustrating situation, and vice versa, accordingly.

It has also been found that the social component of higher education institution adaptation has numerous positive correlations with parameters from other techniques. Let us consider the positive correlation with this component at $p<0.001$ significance level. The following mutual links of the said parameter were found: "Positive re-evaluation" $(r=0.47)$, "Satisfaction by situation" ( $r=0.44)$, "Satisfaction by communication" ( $r=0.48)$, "Acceptance of oneself" ( $r=0.59)$, "Acceptance of others" ( $r=0.64)$, "Emotional comfort" ( $r=0.52)$, "Expectation of internal control" $(r=0.54)$. Thus, we can say that if the social adaptedness level goes up, then students perceive the current situation the new social environment, themselves in a more sensible and positive way, and, as a consequence, their emotional comfort level increases, and vice versa, accordingly.

Let us discuss the professional component of higher education institution adaptation in the personality structure of students coming from other regions. At the stage of correlation analysis, numerous positive correlations were revealed between this characteristics and scales from other techniques. Let us outline the correlations of "Professional adaptation" scale at $p<0.001$ significance level: "Acceptance of oneself" ( $r=0.46)$, "Acceptance of others" ( $r=0.43)$, "Expectation of internal control" $(r=0.48)$. Therefore, higher indices for this adaptation component will involve higher levels of selfacceptance, positive perception of others, internality, and vice versa, accordingly.

Further on, we analyzed the correlation relations of mutual influence between the scales "Social adaptation", "Didactic adaptation", "Professional adaptation" and scales from other techniques with which significant correlations were 
found.

In the personality structure of students who before matriculation lived in the same region as their educational institution is located, the positive correlations of the said component of higher education institution adaptation and two types of motivation during learning were revealed: the one to obtain knowledge (OK) and the one to receive a diploma $(\mathrm{Rd})$. This stage of analyzing the empirical data obtained allows us to make a conclusion that it is the learner's motivational sphere orientation that determines his level of didactic adaptedness (DA) ( $\eta^{2}$ DAlok no influence at the statistically significant level was found; $\eta^{2} \mathrm{OK}_{\mathrm{IDA}}=1 ; p<0.01 ; \eta^{2} \mathrm{DARd}=$ no influence at the statistically significant level was found; $\eta^{2}$ Rd/DA $\left.=1 ; p<0.01\right)$. As focusing the efforts on receiving a diploma is unfavorable for further studying, it is important to work with the second component revealed. Thus, at this stage of learning, for a successful adaptation in the didactic sphere, it is important to form in students coming from Yaroslavl region the motivation to obtain new knowledge.

In the personality structure of students coming from other regions, there is a positive correlation between the said component of higher education institution adaptation and the "Expectation of internal control" (EIC) parameter. At this stage of analysis, we can conclude that it is this index that determines the level of adaptedness in the academic sphere and not vice versa ( $\eta^{2}$ DAEIC no influence at the statistically significant level was found; $\eta^{2} E I C I D A=0.77 ; p<0.01$ ). Thus, the more characteristic it is for the students coming from other regions to undertake responsibility in a problem situation, the higher their level of didactic adaptedness is. The "Motivation to receive a diploma" parameter correlates negatively with the singled out component, too. Having studied the correlation relations of mutual influence, we can come to a conclusion that it is the orientation of motivation that determines the didactic adaptedness level ( $\eta^{2} \mathrm{DA} / \mathrm{Rd}=$ no influence at the statistically significant level was found; $\eta^{2}$ Rd/DA $=1 ; p<0.01$ ). Thus, as a result of primary diagnostics, the students coming from other regions and having high indices of the said parameter should be referred to a risk group in this component of higher education institution adaptation.

In the personality structure of students coming from Yaroslavl region, the significant positive correlations have been found between the social component and the following parameters: "Acceptance of oneself" (Aos), "Expectation of internal control", "Emotional comfort" (EC) and "Acceptance of others" (A0o). The analysis of correlation relations of mutual influence enables us to conclude that it is these characteristics that influence the level of the said component and not vice versa ( $\eta^{2}$ SAIAos no influence at the statistically significant level was found; $\eta^{2}$ Aos $/ S A=0.86 ; p<0.01 ; \eta^{2}$ sAEIC no influence at the statistically significant level was found; $\eta^{2}$ EICISA $=0.87 ; p<0.01 ; \eta^{2}$ SAIEC no influence at the statistically significant level was found; $\eta^{2} E C / S A=0.70 ; p<0.01 ; \eta^{2} S A / A 00$ no influence at the statistically significant level was found; $\left.\eta^{2}{ }_{A o o} / \mathrm{SA}=0.64 ; p<0.01 ;\right)$. Thus, the more sensible and tolerant is the way students coming from Yaroslavl region perceive the new social environment and themselves, the more satisfied they are with the conditions formed, and in the case of internal type control locus, the higher the indices of the "Social adaptation" parameter will be. It is important to work with the parameters revealed as they have a significant structural weight $(W=52, W=49, W=48, W=47$, respectively) and they are contained in basic personal qualities of students coming from the region. It should also be mentioned that it is this component that determines the extent of satisfaction by activity (AC) in the group of students coming from the region $\left(\eta^{2}\right.$ SAIAC $=0.61 ; p<0.01 ; \eta^{2}$ AC/SA no influence at the statistically significant level was found). Therefore, if we work with this component of adaptation, the students coming from Yaroslavl region will be more satisfied with the new activities they faced when entering the university. Notably, the "Social adaptation" parameter has a rather high structural weight (W=54), which is also quite important for further practical work because by changing this parameter we will be able to influence the entire personality structure of students coming from the region.

In the personality structure of students coming from other regions, there are positive correlations between the social adaptation and such parameters as "Expectation of internal control", "Acceptance of oneself", "Emotional comfort". At this stage of analysis, we can conclude that it is these characteristics that influence the level of social adaptedness and not vice versa ( $\eta^{2}$ SAEIC no influence at the statistically significant level was found; $\eta^{2}$ EICISA $=0.88 ; p<0.01 ; \eta^{2}$ SAIAos $=0.65$; $\eta^{2}$ Aos $/ S A=0.84 ; p<0.01 ; \eta^{2}$ SAIEC no influence at the statistically significant level was found; $\left.\eta^{2} E C / S A=0.61 ; p<0.01 ;\right)$. Thus, in order to influence this component we have to enhance the subjective feeling of emotional comfort, the level of selfacceptance as well as that of internality. With this component, such parameters as "Positive re-evaluation" (PR) and "Acceptance of others" correlate positively, too. Having analyzed the correlation relations of mutual influence between the scales, we can conclude that it is the social adaptedness level that determines the said parameters and not vice versa $\left(\eta^{2}\right.$ SAIPR $=0.61 ; \eta^{2}$ PR/SA no influence at the statistically significant level was found; $p<0.01 ; \eta^{2}{ }_{\text {SAIAoo }}=0.69 ; \eta^{2}{ }_{\text {AoolsA }}=0.65$; $p<0.01 ;)$. Therefore, the more adapted this group of students is to new social conditions is, the more positively they perceive the people around them; and, if a frustrating situation occurs, the more characteristic of them it is to make efforts for creating a positive meaning of the situation, for one's personal growth too. This component of higher education institution adaptation is one of the most important for further practical work with the group of students coming from other regions because it is among the leading ones in the basic personal qualities and it has a high structural weight ( $\mathrm{W}=61)$. 
It should be pointed out that in both groups of students, positive correlations between the social component and such parameters as "Expectation of internal control", "Acceptance of oneself" and "Emotional comfort" are observed. This stage of analysis has enabled us to find out that it is the said parameters that determine the adaptedness level in a new environment. Hence, for enhancing the level of this component of higher education institution adaptation in both groups, we can work with the parameters mentioned.

At the stage of correlation analysis we have found out that in the group of students coming from Yaroslavl region the professional component of higher education institution adaptation correlates positively with such parameters as "Acceptance of oneself", "Expectation of internal control", "Emotional comfort" and "Acceptance of others". Analyzing the correlation relations of mutual influence has allowed us to identify that it is these parameters that influence the level of the said components and not vice versa ( $\eta^{2}$ PA/Aos no influence at the statistically significant level was found; $\eta^{2}$ Aos/PA $=0.71$; $p<0.01 ; \eta^{2}$ PAIEIC no influence at the statistically significant level was found; $\eta^{2}$ EICIPA $=0.86 ; p<0.01 ; \eta^{2}$ PAIEC no influence at the statistically significant level was found; $\eta^{2} E C / P A=0.66 ; p<0.01 ; \eta^{2} P A / A 00$ no influence at the statistically significant level was found; $\left.\eta^{2}{ }_{\text {Aool } P A}=0.68 ; p<0.01 ;\right)$. So, it is important to highlight the significance of the parameters revealed for the practical work with this group of students. It should also be pointed out that just like in the case of social adaptation component, it is the adaptedness level that determines the extent of satisfaction by activity in the group of students coming from the region ( $\eta^{2} \mathrm{PA} / \mathrm{AC}=0.63 ; \eta^{2} \mathrm{AC} / \mathrm{PA}$ no influence at the statistically significant level was found; $\left.p<0.01 ;\right)$. The professional adaptation parameter, just like the "Satisfaction by activity" one are leading in the basic personal qualities of the students coming from Yaroslavl region and they have a high value of structural weight $-W=66$ and $W=53$, respectively. This fact gives evidence about the importance of the qualities revealed in the personality structure of students coming from the region.

In the personality structure of students coming from other regions, positive correlations have been found between the said component of higher education institution adaptation and the following parameters: "Expectation of internal control", "Acceptance of oneself", "Motivation to obtain knowledge". This stage of analysis has enabled us to find out that it is the characteristics that determine the professional adaptedness level ( $\eta^{2}$ PAIEIC no influence at the statistically significant level was found; $\eta^{2} E I C / P A=0.73 ; p<0.01 ; \eta^{2} P A / A o s$ no influence at the statistically significant level was found; $\eta^{2}{ }_{\text {Aos } / P A}=0.77 ; p<0.01 ; \eta^{2} P A / O k$ no influence at the statistically significant level was found; $\left.\eta^{2}{ }^{\circ} / P A=1 ; p<0.01\right)$. Therefore, with the self-acceptance, internality and motivation orientation to obtaining new knowledge increasing, the level of this component will go up accordingly. The above parameter also has a positive mutual link with the "Satisfaction by activity", "Satisfaction by communication" (Sc) and "Positive re-evaluation" (PR). Analyzing the correlation relations of mutual influence between the said scales enables us to conclude that it is the professional adaptedness level that determines the indices and not vice versa $\left(\eta^{2} \mathrm{PA} / \mathrm{AC}=0.61 ; \eta^{2}\right.$ ACIPA no influence at the statistically significant level was found; $p<0.01$; $\eta^{2}$ PAISc $=0.63 ; \eta^{2}$ SCIPA no influence at the statistically significant level was found; $p<0.01 ; \eta^{2}$ PAIPR $=0.62 ; \eta^{2}$ PRIPA no influence at the statistically significant level was found; $p<0.01$;). Thus, if the level of this component of higher education institution adaptation goes up, the level of satisfaction by activity and communication in the new social environment will increase; similarly, in case of a frustrating situation, efforts for creating a positive meaning of the situation are more likely to be made. The "Satisfaction by activity" and "Positive re-evaluation" indices are also leading in the basic personal qualities of the students coming from other regions and they have a high value of structural weight, $W=64$ and $W=59$, respectively. This gives evidence about the importance of these qualities in personality structure of this group of students, and the entire structure will change if there is an attempt to change the above parameters. It should be pointed out that in this group of students all three components of higher education institution adaptation are in a positive correlation with the parameter of "Expectation of internal control". Correlation analysis of mutual influence relations between the scales has enabled us to find out that it is the said parameter that determines level of all components. The scale "Expectation of internal control" has a high structural weight $(\mathrm{W}=57)$ and it is the leading basic personal quality of students coming from other regions. Thus, by influencing this parameter, we can at the same time promote the enhancement of all three components of students' adaptation to the higher education institution as a total.

Next, let us consider the structural indices.

First, we are going to analyze the structure organization index $\left(l_{0}\right)$ which characterizes the uniting of qualities into an integral structure and acts as one of the main prerequisites for ensuring the efficiency of students' adapting to the higher education institution. The structure of students coming from the home region is represented as the least integrated one $\left(l_{0}=222\right)$ while the structure diagram of students coming from other regions is non-differentiated to a smaller extent $\left(I_{0}=294\right)$. This fact allows supposing that this is associated with having to adapt not only to the higher education institution, but also to the new daily life, social and cultural conditions.

Further, let us consider the structure divergence index $\left(I_{d}\right)$ that points to the extent of differentiating trends representation in the structure. This index is significantly higher in students coming from the region $\left(\mathrm{I}_{\mathrm{d}}=82\right)$ as compared 
to students from other regions $\left(l_{d}=74\right)$.

The structure coherence index $\left(\mathrm{I}_{\mathrm{c}}\right)$ has higher values in the personality structure of students coming from other regions $\left(I_{c}=368\right)$ as compared to the group of Yaroslavl region first-year students $\left(I_{c}=304\right)$. Therefore, the qualities revealed in this group of students are synthesized into certain integrity.

We have also analyzed the difference of personality structures and basic qualities in the subdivided student groups using the express $\chi^{2}$ method. The empirical value obtained equals 86.66 . For the error probability $p \leq 0.001$ and $\mathrm{df}=50$, the critical value is $\chi^{2}=123.49$. The empirical value obtained is more than the critical one, therefore, the distinctions of structures are valid.

\section{Conclusion}

Having analyzed and generalized the data obtained, we have come to the following conclusions:

1. The subdivision of non-resident students according to their place of residence before entering the university into two groups - the first-year students coming from Yaroslavl region and ones from other regions - is empirically grounded.

2. The group of students coming from other regions has lower indices of social and professional components of adaptation at the statistically significant level, as compared to the first-year students coming from the region.

3. In the structure of personality of students coming from other regions the parameter "Expectation of internal control" is in a positive correlation and it determines all three components of higher education institution adaptation. Therefore, by influencing this parameter, we can at the same time promote the enhancement of all constituents of students' adaptation as a total.

\section{Acknowledgements}

The work has been performed with the financial support of project No.25.2356.2014K within the project part of the R\&D state assignment to the university.

\section{References}

Chapdelaine, R.S., Alexitch, L. (2004). Social skills difficulty: Model of culture shock for international graduate students. Journal of College Student Development, 45, 167-184.

Karpov, A.V., Orel, V.E., Ternopol, V.Ya. (2003). Psikhologhiya professional'noi adaptatsii [Psychology of professional adaptation]. Yaroslavl: Avers Press.

Khasyanova, M.G., Saltanova, E.V. (2010). Adaptatsiya inogorodnikh studentov kak odin iz aspektov vospitatel'noi raboty v vuze [Adaptation of non-resident students as one of the aspects of morale building at higher education institutions]. Collection of works of the Regional scientific and practical conference "Modern problems of upbringing process at higher education institutions", 165169.

Hertel, J.B. (2002). College student generational status: Similarities, differences, and factors in college adjustment. The Psychological Record, 52 (1), 3-18.

Nishimura, T., Sakurai, S. (2013). The relationship between autonomous motivation and academic adjustment in junior high school students. Shinrigaku Kenkyu, 84 (4), 365-375.

Povarenkov, Yu.P. (2008). Problemy psikhologhii professional'nogo stanovleniya lichnosti [Problems of psychology of a personality's professional rise]. Yaroslavl: Kantsler.

Schmidt C.S. (2005). An exploration into first generation adult student adaptation to college. Doctor of Philosophy Dissertation. Kansas.

Smith M.L. (2008). The Transition to University: Adaptation and Adjustment. Master of Arts Dissertation. Saskatchewan

Trockel, M. Barnes M., Egget D. (2000). Health-related variables and academic performance among first-year college students: Implications for sleep and other behaviors. Journal of American College Health, 49, 125-131.

Yurkina, M.S., Smirnov, A.A. (2015). Psikhologhicheskaya kharakteristika vuzovskoi adaptatsii uchebnykh migrantov [Psychological characteristics of higher education institution adaptation of study migrants]. Sovremennye problemy nauki i obrazovaniya. Retrieved from: http://www.science-education.ru/121-18911 